\title{
AMBIENT VIBRATIONAL CHARACTERIZATION OF THE NOSSA SENHORA DAS DORES CHURCH
}

\author{
Esequiel MESQUITA ${ }^{\mathrm{a}}$, Francisco BRANDÃO ${ }^{\mathrm{b}}$, Aldecira DIOGENES ${ }^{\mathrm{c}}$, \\ Paulo ANTUNES ${ }^{\mathrm{d}}$, Humberto VARUM ${ }^{\mathrm{e}}$ \\ ${ }^{a}$ Laboratory of Civil Engineering, Nucle of Industrial Technology of Ceara, \\ Campus PICI, Fortaleza, 60455-001, Brazil \\ b.c Universidade Estadual Vale do Acarau, Sobral, 62040-370, Brazil \\ ${ }^{d}$ Universidade de Aveiro Departamento de Fisica, Departamento de Física, Aveiro, 3810-193, Portugal \\ ${ }^{e}$ Faculdade de Engenharia da Universidade do Porto, \\ Departamento de Engenharia Civil, Porto, Portugal
}

Received 31 October 2017; accepted 08 December 2017

\begin{abstract}
The present paper shows the vibrational characterization tests of a clay brick heritage construction from XIX century, the Nossa Senhora das Dores Church, placed in Sobral, Brazil. In this study the calibration of the 3D finite element numerical model of the church was performed through ambient vibrational testing using the first three natural frequencies identified. The obtained results, namely the natural frequencies identified, and the calibrated model intends to give a contribute for understanding of the structural behavior of the Brazilian heritage constructions, and introduces relevant information for be used for safety assessment of the church along the time.
\end{abstract}

Keywords: dynamic identification, ambient vibration testing, heritage construction, FEA, OMA.

\section{Introduction}

Heritage constructions (HC) have become an interesting and challenge field for engineering advances due to high variability and complexity of its structural systems and the current necessity of to implement news techniques for non-destructive assessment opened to be integrate with structural monitoring systems. In this way, vibrational methods are one of the most employed techniques for non-destructive assessment reported in the literature (Rytter 1993; Boscato et al. 2016; Mesquita et al. 2017).

In fact, vibrational testing had been applied in different types of structures in order to collect data for dynamic characterization (Beskhyroun et al. 2012; Magalhães et al. 2012; Martins et al. 2014), especially due to possibility of to characterize globally the struc- tures (Yun et al. 2011) and in the case of ambient vibration characterization because they allow the structural characterization without no excitation equipment (Gentile, Saisi 2007). The recent developments on sensors devices, data processing tools, and its application on buildings and infrastructures allowed overcoming several technical issues on this field (Ivanovic et al. 2000; Brownjohn 2003; Spencer et al. 2004; Hans et al. 2005), however cases involving vibration characterization of $\mathrm{HC}$ had been rarely reported in the literature, especially out of European zone (Mesquita et al. 2016).

Ambient vibration measurements were obtained and analyzed by (Potenza et al. 2015) for to characterize and monitoring the Basilica di Santa Maria Col- 
lemaggio, in Italy. The partial collapse of the church after L'Aquila earthquake in 2009, make increase the uncertainties on its structural behavior, motivating the necessity of characterization and monitoring of this historical construction from Italian Romanesque period. The church was instrument by accelerometers and the data collected allowed the dynamic characterization of the church. The contributions of this work can be summarized in terms of the dynamic behavior identification of the church, as well by description of the strategies employed for vibrational testing.

Essentially, the identification of the structural dynamic properties are an useful tool for safety analysis, making possible the investigation of damages influence on global behavior of structures, as previously demonstrated (Potenza et al. 2015). Moreover, this tool can also provide useful information for be used in support of structural risk reduction, as for instance for be used in accordance with proceedings described in (dei Ministri 2011) and (CIB 2010).

In (Gentile, Saisi 2007), an ambient vibration testing was carried out in order to provide complementary information on the bell-tower of the Cathedral of Monza, Italy. This work presented a simplified methodology for dynamic characterization based on data come from Operational Modal Analysis (OMA), and the results allowed optimizing a 3D finite element model for be used in the support of the safety analysis of the tower under different loadings conditions. The authors highlight that this approach seems a promising way of to assess $\mathrm{HC}$ globally, especially for to analysis the impact of hypothetic scenarios of damage to structural safety.

Optimized procedures for dynamic identification of heritage constructions are described in (Boscato et al. 2016). In this report the authors provided useful information for ambient vibration characterization of churches, towers and palaces, as for instance the general range of fundamental frequencies found experimentally, namely standing between $2.5 \mathrm{~Hz}$ and $7 \mathrm{~Hz}$, while the frequencies around $1.50 \mathrm{~Hz}$ are mostly related with domes and façades. Moreover, the authors highlight the existence of a lack of knowledge on structural behavior of heritage construction, making necessary some efforts by technical-scientific community, to overpass this issue.

The present work was developed with the main aim of identifying the dynamic properties of the Nossa Senhora das Dores Church, located in Sobral, Brazil, through a theoretical-experimental based strategy. In the paper, an ambient vibration procedure was carried out to identify the natural frequencies of the Nossa Senhora das Dores Church (see Fig. 1), in order to collect information for updating a 3D finite element model that will allow to proceed with assessment of the structural condition of the church. The ambient

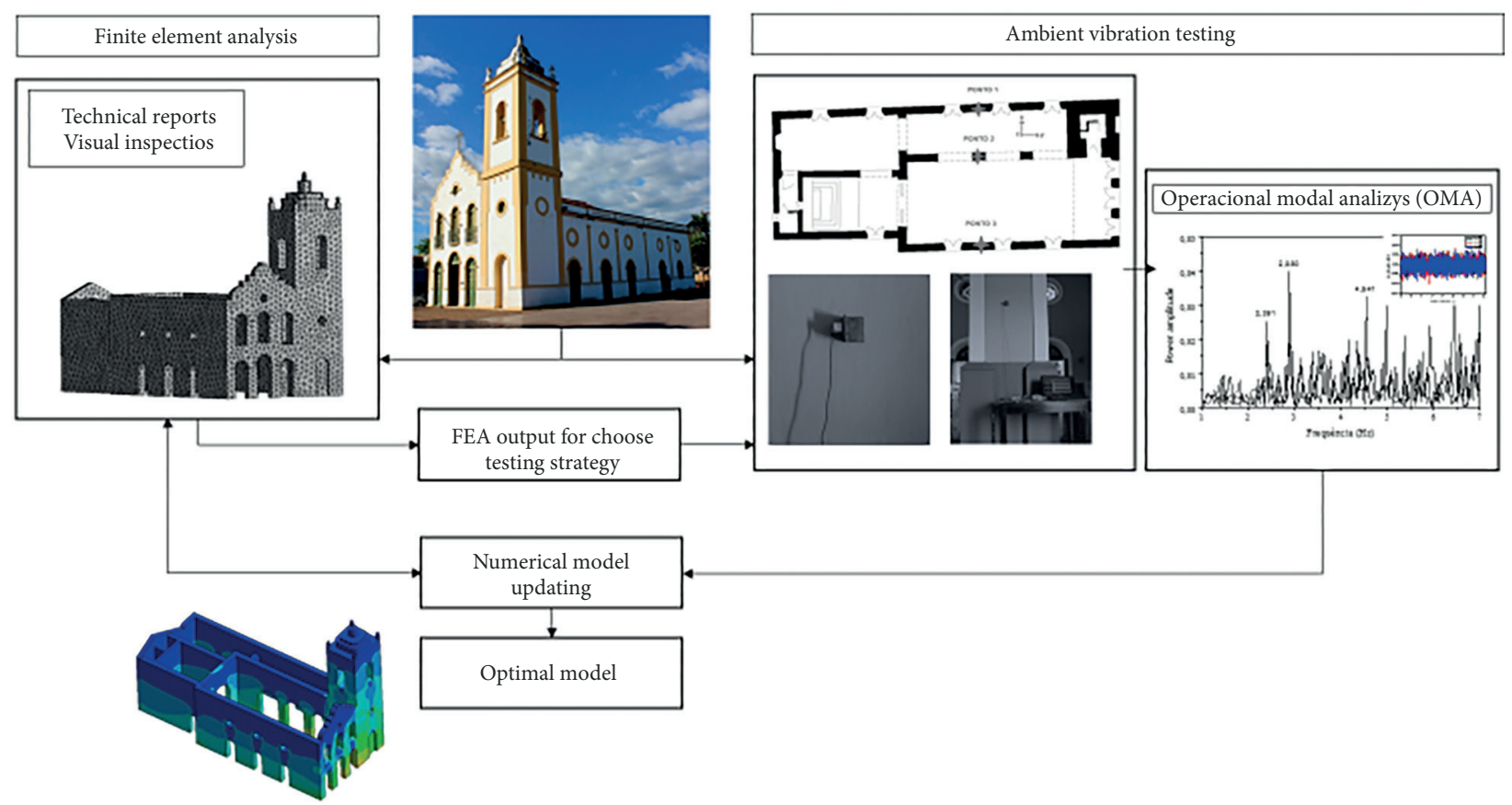

Fig. 1. Ambient vibration procedure used for Nossa Senhora das Dores Church characterization 
vibration procedure carried out in this work included the following main steps:

i. Finite Element Analysis (FEA);

ii. Ambient vibration testing;

iii. Operational modal analysis;

iv. Numerical model updating.

Additionally, no report was identified in the technical literature concerning ambient vibration characterization of Brazilians HC by OMA, making from this work an important contribution for study and understanding of the structural behavior of Brazilian ancient structures.

\section{Theoretical background}

Operational Modal Analysis is based on the measurement of structural modal responses only due to the action of ambient and operational forces. This method is usually employed for modal characterization of large constructions, as bridges, towers, offshore structures and buildings, considering that the environmental and operational forces (random forces) are sufficient for the structural excitation (Magalhães et al. 2012).

Essentially, the modal parameters collected in field measurements are commonly used for calibrating numerical models, and one of the primary data analyses methods applied is the Fast Fourier Transform (FFT).

The FFT can be understood as a Fourier series which the periodic signal is the sum of an infinite number of harmonic signals, or in another words, using the FFT function the time domain signals recorded in field can be resolved in terms of its frequency components (Magalhães 2010) and can be obtained by the Expression 1, where $F(x)$ is the FFT function, $\mathrm{L}$ is the interval analyzed (in this ranging $-L \leq x \leq L$ ) and a and $\mathrm{b}$ are coefficients according to interval $\mathrm{L}$.

$$
F(x)=a_{0}+\sum_{n=1}^{\infty}\left(a_{n} \cos \frac{n \pi x}{L}+b_{n} \sin \frac{n \pi x}{L}\right) .
$$

One of the simplest method used in OMA is the peak-picking, employed for identification of the frequency of vibrations in OMA, basically due to the fact that this method consists in the identification of the peaks of the frequency spectrum obtained by the processed power spectrum domain data.

The relation between the random excitation forces $F(t)$ and the spectral responses $X(t)$ can be described in the frequency domain through the Frequency Response Function $(F R F), H(w)$, according to Expression 2, where $\operatorname{SFF}(w)$ and $S_{X X}(w)$ are the PSD matrices of the random excitation forces and spectral response, and $T$ indicated conjugate and transpose operation (Le, Tamura 2009).

$$
S_{X X}(w)=H(w) S_{F F}(w) H^{T}(w) .
$$

However, the FRF can be also described in partial fraction, as pole/residue, as suggested by (Brincker et al. 2001) and presented by Expression 3, where $N$ is the number of modes, $i$ is the index of mode, $A_{i}$ and $\lambda_{i}$ are residue and pole, respectively, when $A_{i}=\gamma_{i} \phi_{i} \phi_{i}^{*}$ and $\lambda_{i}=\zeta_{i} w_{i}+j w_{i} \sqrt{1-\zeta_{i}^{2}}$, noting that $\zeta_{i}$ represents the modal damping ratio, and $\gamma_{i}$ and $\phi_{i}$ are the scaling factor and modal shape vector, respectively. So, this is a modal decomposition of the spectral matrix and the expressions 7 and 8 can be directly related, under the hypothesis of independent white noise input.

$$
\begin{aligned}
& H(w)=\sum_{i=1}^{N}\left(\frac{A_{i}}{j w-\lambda_{i}}+\frac{A_{i}^{*}}{j w-\lambda_{i}^{*}}\right)= \\
& \sum_{i=1}^{N}\left(\frac{\gamma_{i} \phi_{i} \phi_{i}^{*}}{j w-\lambda_{i}}+\frac{\gamma_{i}^{*} \phi_{i}^{*} \phi_{i}^{*} T}{j w-\lambda_{i}^{*}}\right) .
\end{aligned}
$$

\section{The Nossa Senhora das Dores Church}

Nossa Senhora das Dores Church (Fig. 2) is a clay brick historical structure, built on 1880s, placed at Sobral downtown, near of the Acaraú river. Sobral is located at north of Ceará State, in Brazil, $230 \mathrm{Km}$ away from Fortaleza. The city was founded on XVII century, and presents one of the biggest historical centers of Brazil, with over around 1200 buildings classified since 2009 by Instituto do Patrimônio Histórico e

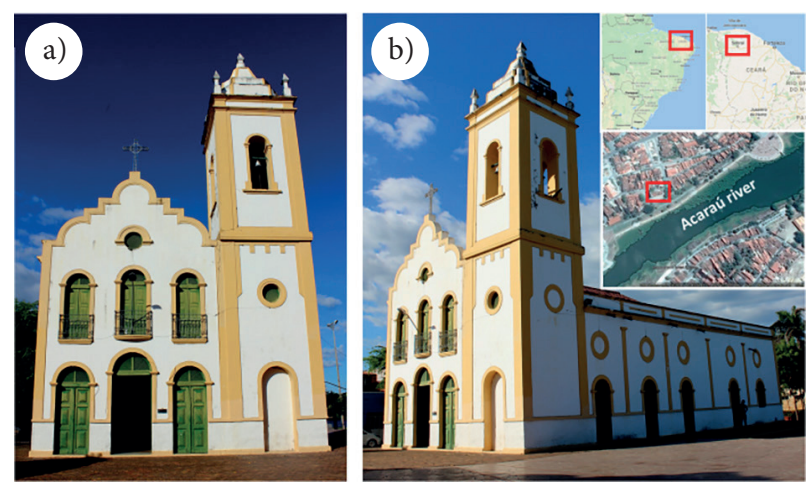

Fig. 2. Nossa Senhora das Dores Church: a) main façade and b) lateral view of the church 
Artístico Nacional (IPHAN). Since 2008, some seismic events had been registered at Sobral region, and the continuous monitoring had confirmed that its occurrence is each more often.

The church façade presents two levels, the first with three arched doors, and the second level with the arched windows aligned with the doors of the first level. The façade can be characterized as architectural neoclassic style, however the lateral bell-tower (Fig. 2b) does not follow the same architectural style, because its construction just was finished in 1924 .

The church presents a regular geometry with $26.17 \mathrm{~m}$ of length and $11.87 \mathrm{~m}$ of width, and a maximum high of $20.50 \mathrm{~m}$ (the tower), and it is divided in a Central Nave separated from a Lateral Nave by two columns and three arches, the Coro-Alto, the lateral bell-tower, the Altar-Mor and an office (in the end of the building). The Figure 3 shown a schematic view of the geometry of the Nossa Senhora das Dores Church, while Figure 4 presents details of the interior of the church.

A visual inspection carried out, on the Nossa Senhora das Dores Church, allowed the identification of the main damages present on the façades and to build a damage map, shown by Figure 5. Firstly, the damages will be not considered in the FEA, however the damage mapping will be used as support for interpretation of the numerical model results. The main damages identified on the church are related with cracks (surrounding the opened areas), biological attacks and mortar detachment. In general, these damages are related with material decaying, and does not present risk to structural safety of the church. Figure 6 illustrates the type of damages found on the church.

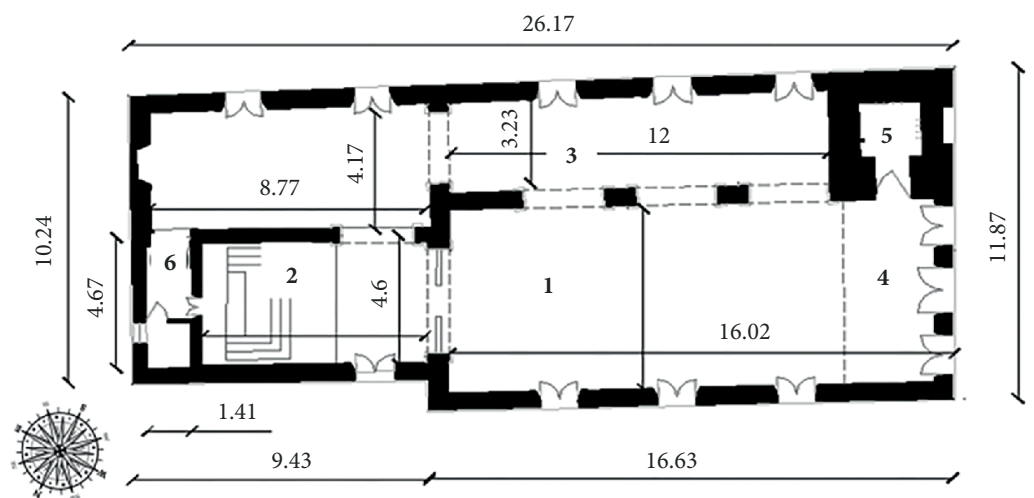

Fig. 3. Schematic cut of geometry of the Nossa Senhora das Dores Church, where 1 is the Central Nave, 2 is the Altar-Mor, 3 is the lateral Nave, 4 - is the Coro-Alto, 5 is the bell-tower and 6 is the office
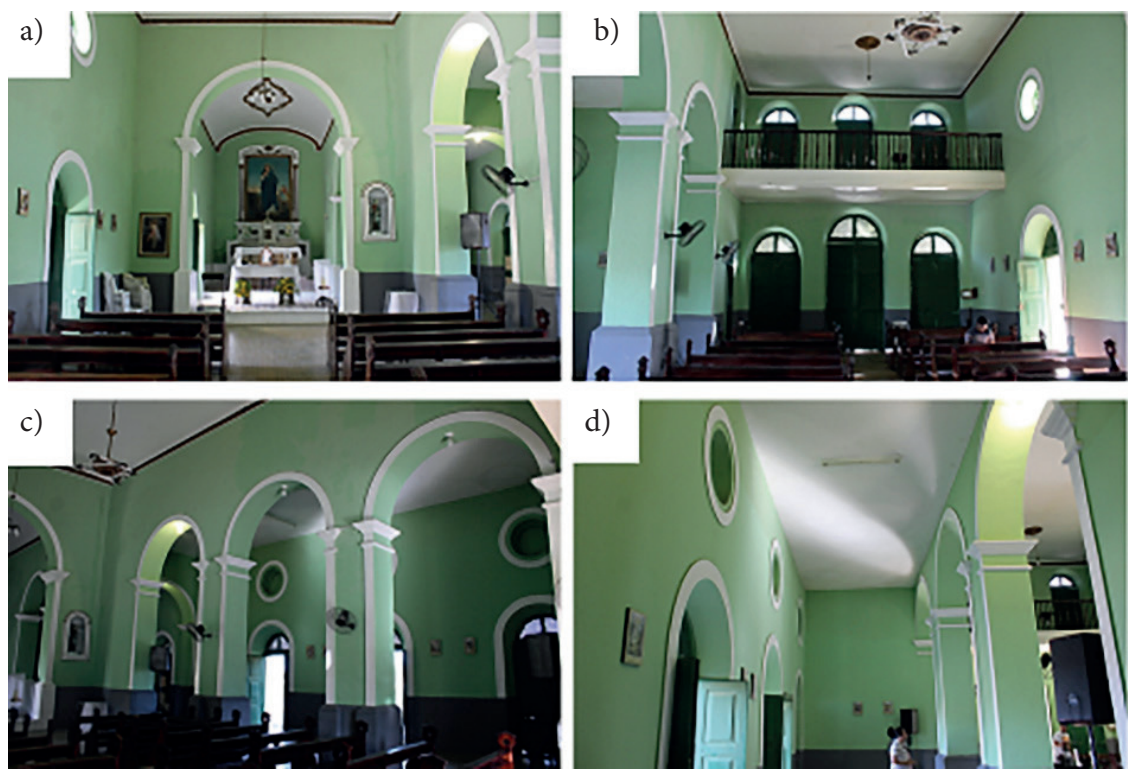

Fig. 4. Interior of the Nossa Senhora do Rosário Church: a) Altar-Mor; b) Central Nave and Coro Alto; c) columns and arches and d) lateral Nave 

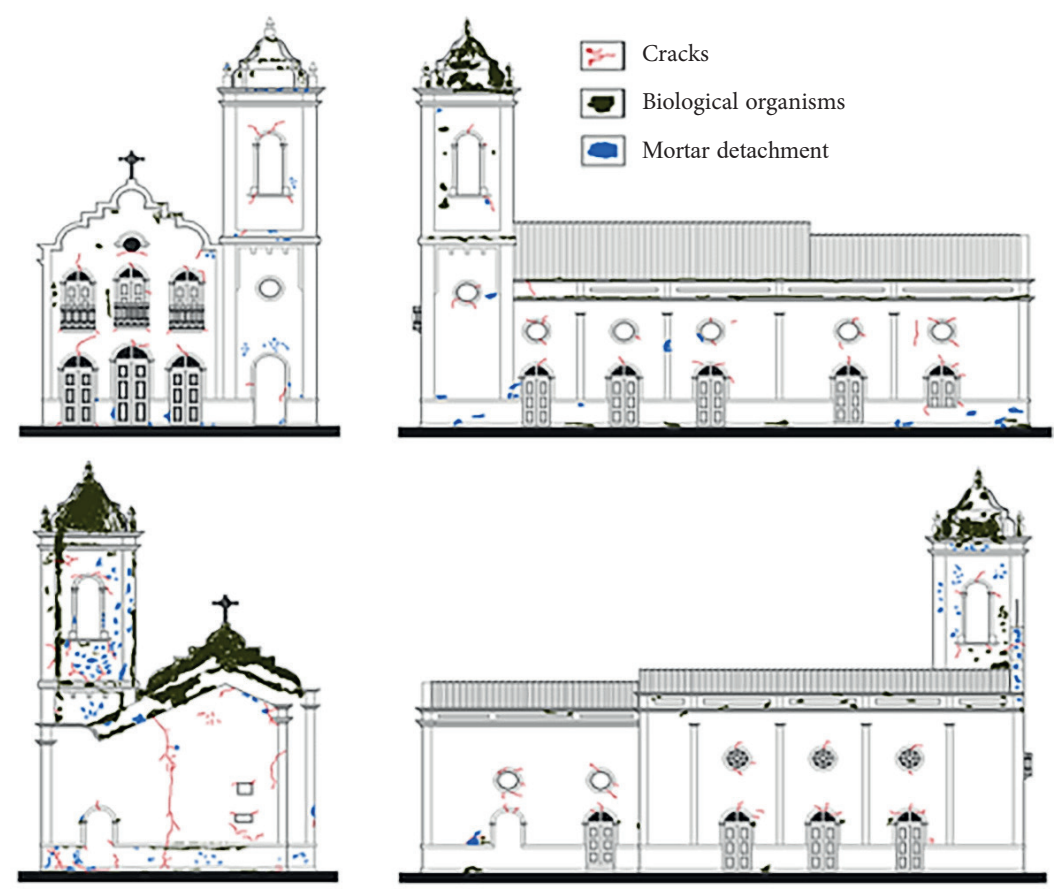

Fig. 5. Damages mapping of Nossa Senhora das Dores Church
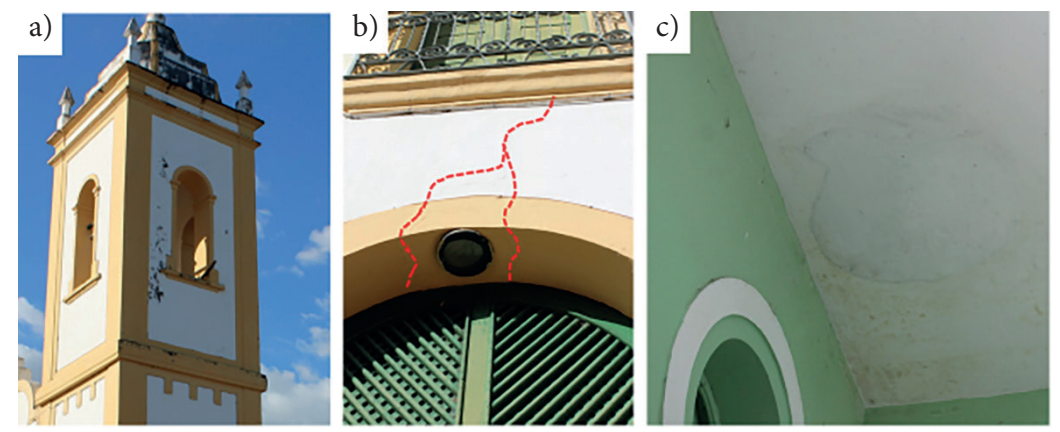

Fig. 6. Examples of the damages found during the inspection on Nossa Senhora das Dores Church: a) degradation by biological action; b) cracks in the arches and c) humidity presence in the slab roof

\section{Finite element modeling}

Before the ambient vibration testing be carried out on the Nossa Senhora das Dores Church, a 3D (Fig. 7) model was built based on the geometric survey. Some simplifications were done in the numerical model to reduce possible discontinuities in the finite element frame, as for instance the roofs and the Coro-Alto were not considered for the model. In the same direction, the architectural details in the main façade were simplified, and a constant thickness of $0.60 \mathrm{~m}$ was adopted to the walls. Exceptionally, the walls indicated in the Figure $7 b$, at the end of the Altar-Mor and the wall inside of the office, presents thickness of $0.35 \mathrm{~m}$ and $0.15 \mathrm{~m}$, respectively.

The stairs, the timber structure of the Coro-Alto, and the roofs were not modeled, however equivalent

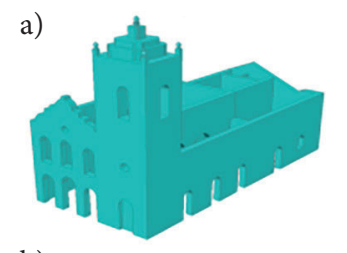

b)

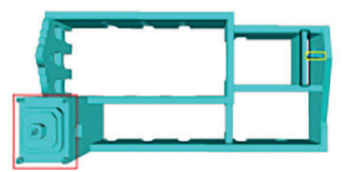

c)

Fig. 7. 3D finite element model of the Nossa Senhora das Dores Church: a) lateral view of 3D model; b) top view of the 3D model and c) 3D model with finite element frame

loads and mass were considered in the numerical model. The reinforced-concrete stair presents a "L" form and goes on till maximum high of $10.00 \mathrm{~m}$. This way, 
according to NBR 6120 (ABNT 1980), the stair loading was assumed as $3 \mathrm{kN} / \mathrm{m}^{2}$, and it was uniformly distributed at the top surface of the four tower walls. For the Coro Alto loading a timber type Pine was considered and its specific weigh, $\gamma$, of $5 \mathrm{kN} / \mathrm{m}^{3}$ (ABNT 1980) was used for calculate its load, taking into account the geometric measures of the Coro Alto. This way, for each support of the Coro Alto floor, a load of $1.75 \mathrm{kN} / \mathrm{m}^{2}$ was applied. Following, the roof consists in a timber structure, where the ceiling tiles are supported, and in the bottom a ceiling plaster, usually adopted in the region, is fixed in the timber structure. For the ceiling plaster a loading value of $0.60 \mathrm{kN} / \mathrm{m}^{2}$ was adopted, the same value adopted by (Branco 2007). For the roof load was stated as $1.30 \mathrm{kN} / \mathrm{m}^{2}$, the same value adopted in (Neves 2008). Moreover, an additional loading of $0.75 \mathrm{~N} / \mathrm{m}^{2}$ was applied on the roof. This way, the total loading of the roof was of $2.65 \mathrm{~N} / \mathrm{m}^{2}$, and that value of load was distributed along of the walls that support the roofs element.

Concerning the mechanical properties of the clay brick used, initially were considered the values reported in the literature due to the impossibility of to proceed with in situ mechanical characterization. The Elastic Modulus (E), Specific Weight (W) and the compressive strength $\left(f_{m}\right)$ were stated based in (Ministero Delle Infrastrutture E Dei Trasporti 2008). The Poisson coefficient $(v)$ was adopted as 0.20 , according to (Branco 2007; Delgado 2013; Ortega et al. 2015). The tensile strength was stated as $5 \%$ of the compressive strength, as usually is adopted in analytic software as 3muri (STA Data 20017). Table 1 summarizes the mechanical properties of the clay brick masonries adopted in the numerical model.

Table 1. Mechanical properties of the clay brick masonries adopted to numerical model

\begin{tabular}{|c|c|c|c|c|}
\hline $\mathrm{E}(\mathrm{GPa})$ & $\mathrm{W}\left(\mathrm{kN} / \mathrm{m}^{3}\right)$ & $f_{m}(\mathrm{MPa})$ & $f_{t}(\mathrm{MPa})$ & $v$ \\
\hline 1.50 & 18.00 & 3.20 & 0.16 & 0.20 \\
\hline
\end{tabular}

The FEA was performed with Ansys ${ }^{\circ}$, and the numerical model of the Nossa Senhora das Dores Church resulted in 93380 nodes, 53889 tetrahedral elements with 6 degrees of freedom each one. The element SOLID187 was used due to his compatibility with irregular and curved surfaces. The details of the finite element frame can be observed through Figure $7 \mathrm{c}$. The church footing was considered with fixed translations and the numerical model was considered as unique solid.

\section{Ambient vibrational characterization}

\subsection{Experimental setup and natural frequencies identification}

The experimental testing was carried out according to experimental setup shown in Figure 9 in April, $28^{\text {th }}$ 2016. The accelerometers positioning were defined based on previous numerical results through FEA, where the initial configurations of the modal shapes of the church were obtained. For data collect, a triaxial accelerometer, with frequencies record between $0 \mathrm{~Hz}$ and $100 \mathrm{~Hz}$, controlled through a LabView software (Fig. 8) developed by Institute of Telecommunications of Aveiro, was used. The data acquisition system re-

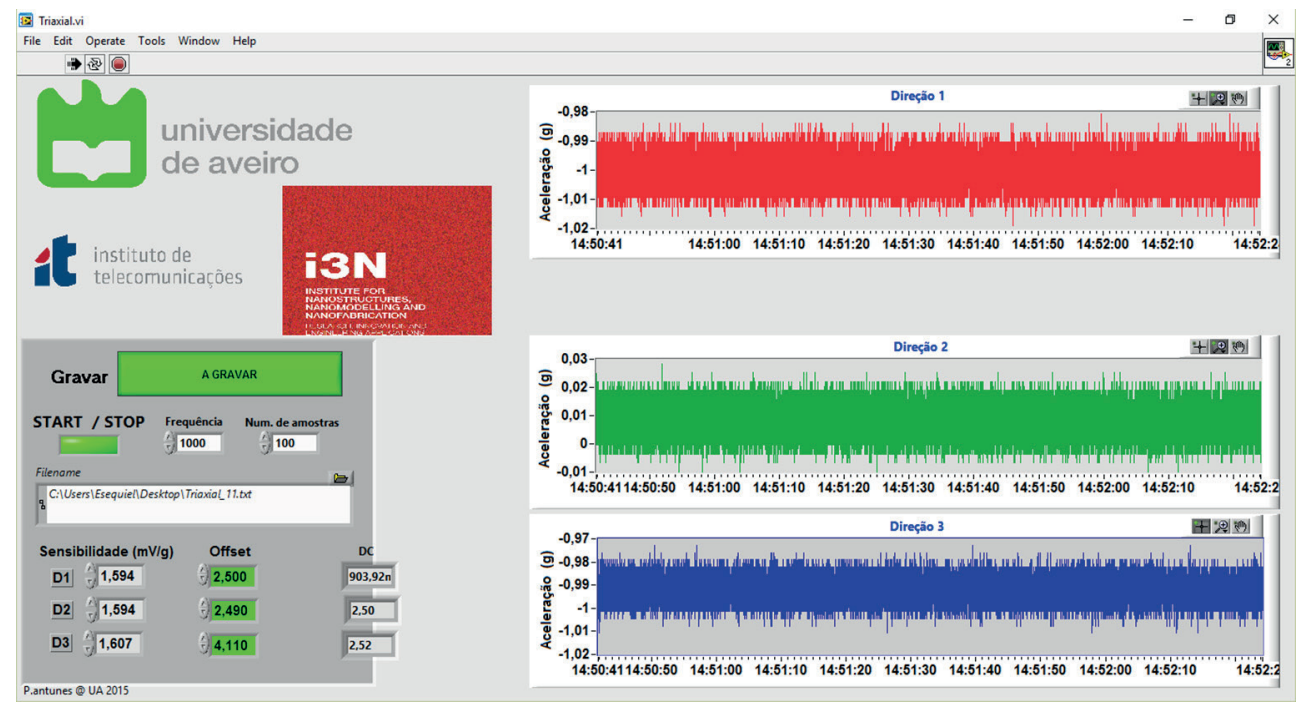

Fig. 8. Interface of the software used for data acquisition 


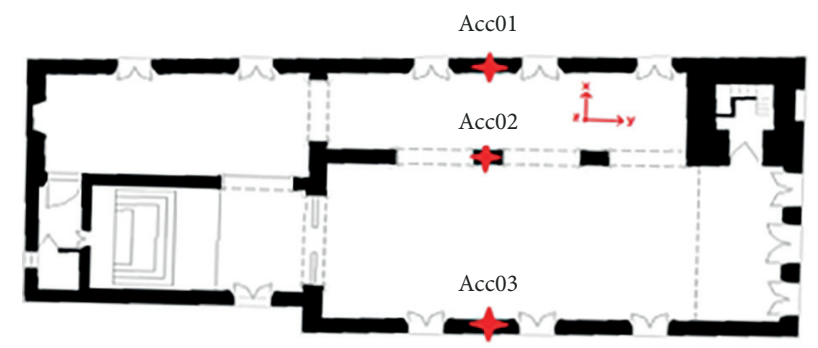

Fig. 9. Accelerometers positioning and data collecting

cord acceleration data during $10 \mathrm{~min}$. The accelerometers were placed $3.00 \mathrm{~m}$ of high from the footing of the church, and details of the sensors positioning, and data collecting can be observed by Figure 8 .

Accelerations in 3 directions were recorded during 600seconds in each measure point as assigned by Figure 9. The $\mathrm{X}$ direction was considered as out-ofplane of the walls (transversal direction), and Y direction was stated as in the plane of the walls (longitudinal direction), while $\mathrm{Z}$ was considered as vertical direction.

For OMA, the accelerations register in the $\mathrm{X}$ and $\mathrm{Y}$ direction (Fig. 10) were processed by Fast Fourier Transformer (FFT), with recurrence to commercial software SeismoSignal. For that 16384 points were used, once that FFT request samples in the form $2^{\mathrm{x}}$, in this case $2^{14}$, with a time interval of $0.001 \mathrm{~s}$.

The data collect in the vertical direction $(\mathrm{Z})$ were not considered in the OM, once based on the preliminary analysis, and as expected, of the signal amplitudes demonstrates that in the vertical direction the church does not present significant values in comparison with signal amplitudes observed in $\mathrm{X}$ and $\mathrm{Y}$ direction, moreover, the FEA demonstrates that in $\mathrm{Y}$ direction the effective modal mass is not expressive. Following,

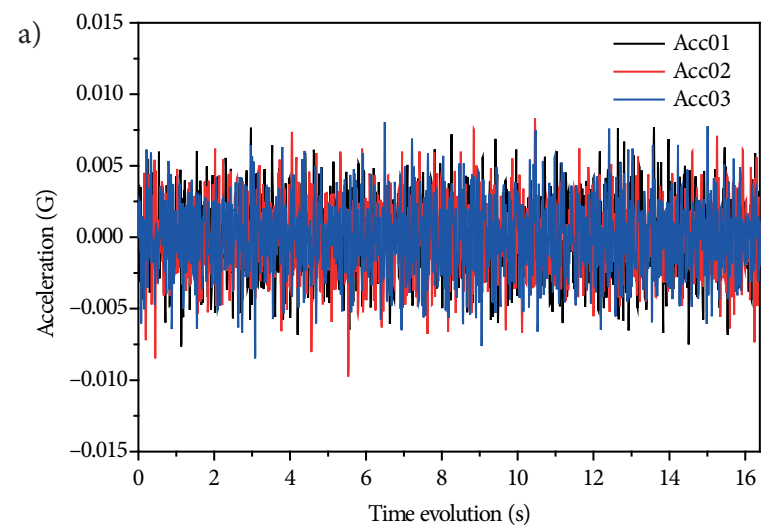

from FEA it was expected to find natural frequencies with values higher then $1.50 \mathrm{~Hz}$, making possible submit the signal by a Lowpass and Bandpass filters, namely between the range from $1.00 \mathrm{~Hz}$ to $30.00 \mathrm{~Hz}$. Additionally, the amplitude of the frequencies between 0 and $1.00 \mathrm{~Hz}$ were not superior to $0.01 \mathrm{~Hz}$, making adequate the employment of the filters between the ranges specified.

From acceleration recorded, the data processing allowed to plot the signal in the frequency domain, as can be seen in Figure 10, and the natural frequencies in $\mathrm{X}$ and $\mathrm{Y}$ were identified through well-known Peak Picking method. The fundamental frequencies identified are presented in Table 2.

Table 2. Natural frequencies identified through ambient vibration testing of the Nossa Senhora das Dores Church

\begin{tabular}{|c|c|l|}
\hline Mode & Frequency $(\mathrm{Hz})$ & \multicolumn{1}{|c|}{ Mode type } \\
\hline 1 & 2.391 & $\begin{array}{l}\text { Transversal bending } \\
\text { (X direction) }\end{array}$ \\
\hline 2 & 2.880 & $\begin{array}{l}\text { Possible Torsional mode } \\
\text { (X and Y direction) }\end{array}$ \\
\hline 3 & 3.125 & $\begin{array}{l}\text { Longitudinal bending } \\
\text { (Y direction) }\end{array}$ \\
\hline 4 & 3.466 & $\begin{array}{l}\text { Longitudinal bending } \\
\text { (Y direction) }\end{array}$ \\
\hline 5 & 4.541 & $\begin{array}{l}\text { Transversal bending } \\
\text { (X direction) }\end{array}$ \\
\hline
\end{tabular}

Analyzing the spectrum of frequencies presented by Figure 11, it can be noted that the first five frequencies identified by OMA are between $2.00 \mathrm{~Hz}$ and $5.00 \mathrm{~Hz}$. The first natural frequency was identified as $2.391 \mathrm{~Hz}$, in transversal mode (X direction), while the second natural frequency was identified in both direction, being admitted as $2.880 \mathrm{~Hz}$, in a possible torsion

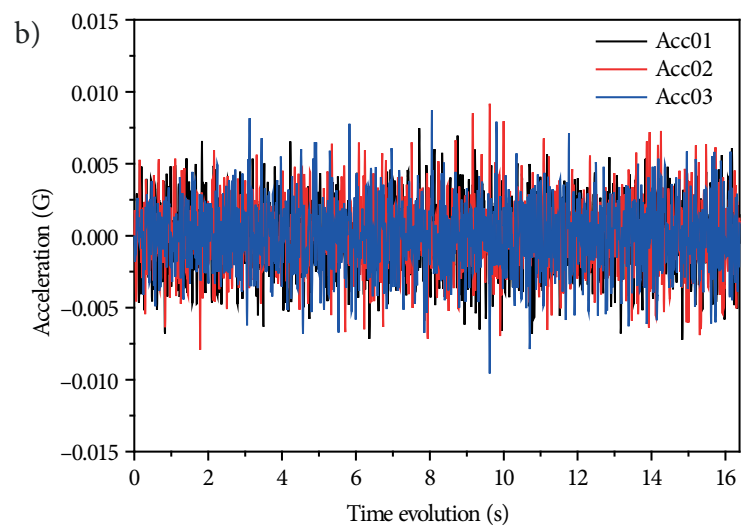

Fig. 10. Firsts 16s of the acceleration registered on Nossa Senhora das Dores Church: a) accelerations collected in $\mathrm{X}$ direction and $\mathrm{b}$ ) accelerations collected in $\mathrm{Y}$ direction 

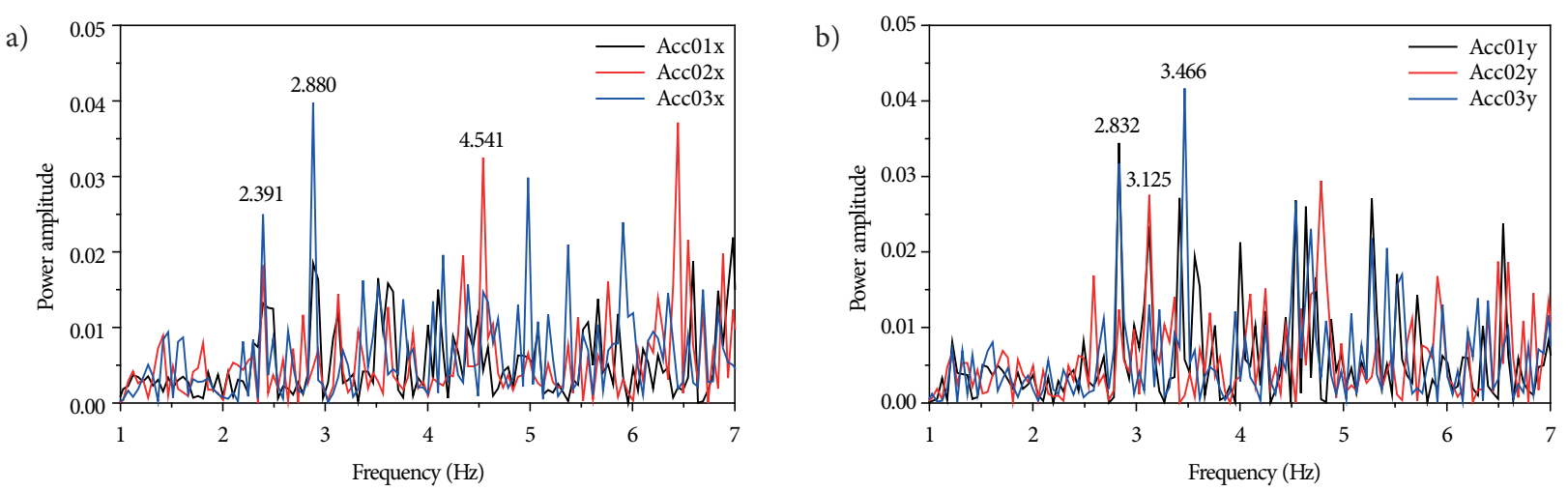

Fig. 11. Frequencies spectrum obtained by OMA of the Nossa Senhora das Dores Church

configuration. The third and fourth frequencies, respectively $3.125 \mathrm{~Hz}$ and $3.466 \mathrm{~Hz}$ were observed in $\mathrm{Y}$ direction, characterized by a longitudinal mode, while the fifth fundamental frequency was characterized as $4.541 \mathrm{~Hz}$, in a transversal mode.

\subsection{Numerical model updating}

The numerical model updating of the Nossa Senhora das Dores Church was done based on natural frequencies obtained by OMA. The first three natural frequencies were considered sufficient for calibrating the numerical model, where the mechanical properties shown in Table 1 were kept. The Elastic modulus was selected has "updating parameter" and interactively modified to minimize the differences between the natural frequencies obtained by FEA and OMA. This way, the Elastic modulus ranged between $1.50 \mathrm{GPa}$ till maximum value of $1.80 \mathrm{GPa}$, stated as maximum value of Elastic modulus for masonries, according to (Ministero Delle Infrastrutture E Dei Trasporti 2008). After some adjusts proceeding, the optimal value of Elastic modulus was stated as $1.70 \mathrm{GPa}$ and then, the first numerical frequencies were obtained and compared with frequencies obtained by OMA, as shown Table 3.

The difference between the dynamic properties obtained by FEA and OMA can be related with uncertainties during the modeling process, as for instance the mechanical properties of the material and

Table 3. Comparison between FEA and OMA frequencies

\begin{tabular}{|c|c|c|c|}
\hline Mode & $\begin{array}{c}\text { OMA frequencies } \\
(\mathrm{Hz})\end{array}$ & $\begin{array}{c}\text { FEA frequencies } \\
(\mathrm{Hz})\end{array}$ & Error (\%) \\
\hline 1 & 2.391 & 2.403 & 0.502 \\
\hline 2 & 2.880 & 2.806 & 2.637 \\
\hline 3 & 3.125 & 3.084 & 1.329 \\
\hline
\end{tabular}

geometry simplification. In literature, it is usual the recurrence to ambient vibration testing information for calibrating numerical models, and the natural frequencies presents the summarized information of the modal parameters of the structure (Brownjohn 2003; Gentile, Saisi 2007; Magalhães et al. 2012; Ubertini et al. 2013). Usually, $5 \%$ is the maximum acceptable divergence between the experimental and numerical frequencies after numerical model calibration. In this work, the maximum divergence between the frequencies analyzed was of $2.63 \%$, bellow of the limit of error of $5 \%$. The mechanical properties of the clay brick masonries after numerical model updating are presented in Table 4.

With the updated numerical model, the firsts twenty natural frequencies and natural mode shapes were obtained, as well the percentage of effective modal mass for each modal shape of the Nossa Senhora das Dores Church (see Table 5).

The sum of effective modal mass for the first twenty modal shapes in the directions $\mathrm{X}, \mathrm{Y}$ and $\mathrm{Z}$ are $72.930 \%, 61.675 \%$ and $0.151 \%$ respectively. The direction $\mathrm{X}$ presents the higher percentage of effective modal mass indicating that the modal displacements in the transversal direction of the church can be more easy found, as initially indicated by first fundamental frequency identified by OMA. The Y direction also

Table 4. Mechanical properties of the numerical model after updating

\begin{tabular}{|c|c|c|c|c|c|}
\hline $\mathrm{E}(\mathrm{GPa})$ & $\begin{array}{c}\mathrm{W} \\
\left(\mathrm{kN} / \mathrm{m}^{3}\right)\end{array}$ & $\begin{array}{c}f_{m} \\
(\mathrm{MPa})\end{array}$ & $\begin{array}{c}f_{t} \\
(\mathrm{MPa})\end{array}$ & $v$ & \\
\hline 1.70 & \multirow{2}{*}{18.00} & \multirow{2}{*}{3.20} & \multirow{2}{*}{0.16} & \multirow{2}{*}{0.20} & Updated \\
\hline 1.50 & & & & & Initial values \\
\hline $\begin{array}{c}\sim 12 \% \\
\text { variation }\end{array}$ & & & & & \\
\hline
\end{tabular}


Table 5. Modal informations of the Nossa Senhora das Dores Church

\begin{tabular}{|c|c|c|c|c|c|}
\hline \multirow[t]{2}{*}{ Mode } & \multirow{2}{*}{$\frac{\text { Frequency }}{f(\mathrm{~Hz})}$} & \multirow{2}{*}{$\frac{\text { Period }}{T(\mathrm{~s})}$} & \multicolumn{3}{|c|}{ Effective modal mass } \\
\hline & & & $U_{x}(\%)$ & $U_{y}(\%)$ & $U_{z}(\%)$ \\
\hline 1 & 2.403 & 0.416 & 13.533 & 0.219 & 0.000 \\
\hline 2 & 2.806 & 0.356 & 20.969 & 3.020 & 0.003 \\
\hline 3 & 3.084 & 0.324 & 7.241 & 16.007 & 0.010 \\
\hline 4 & 3.342 & 0.299 & 0.022 & 4.951 & 0.008 \\
\hline 5 & 3.796 & 0.263 & 3.031 & 0.008 & 0.000 \\
\hline 6 & 4.925 & 0.203 & 3.571 & 0.211 & 0.000 \\
\hline 7 & 5.547 & 0.180 & 7.051 & 2.271 & 0.001 \\
\hline 8 & 6.229 & 0.161 & 0.581 & 2.311 & 0.001 \\
\hline 9 & 6.753 & 0.148 & 0.628 & 0.558 & 0.001 \\
\hline 10 & 7.247 & 0.138 & 0.019 & 4.143 & 0.003 \\
\hline 11 & 7.867 & 0.127 & 3.864 & 0.147 & 0.000 \\
\hline 12 & 8.192 & 0.122 & 0.993 & 0.013 & 0.001 \\
\hline 13 & 8.591 & 0.116 & 1.437 & 0.212 & 0.000 \\
\hline 14 & 8.763 & 0.114 & 0.943 & 0.729 & 0.003 \\
\hline 15 & 8.924 & 0.112 & 0.950 & 0.001 & 0.001 \\
\hline 16 & 9.275 & 0.108 & 0.720 & 4.703 & 0.001 \\
\hline 17 & 9.463 & 0.106 & 1.851 & 13.502 & 0.049 \\
\hline 18 & 9.907 & 0.101 & 0.526 & 8.546 & 0.026 \\
\hline 19 & 10.341 & 0.097 & 4.412 & 0.062 & 0.027 \\
\hline 20 & 10.835 & 0.092 & 0.588 & 0.060 & 0.017 \\
\hline
\end{tabular}

presents significant influence to modal shapes, with $11.225 \%$ less than effective modal mass from X. However, in $\mathrm{Z}$ direction, the effective modal mass was practically zero. The modal displacements in each one of the twenty modal shapes extracted are shown in Figure 11, indicating the effective modal mass influence for higher displacements in direction $\mathrm{X}$. The negative values presented by Figure 12 indicates that the modal deformation occurred in the negative direction of the references axes adopted in this analysis.

The first three modal shapes are represented in Figure 12, where the first mode is characterized by a bending mode located in the lateral left wall, with maximum modal displacement of 0.215 in the $\mathrm{X}$ direction (Fig. 12a). The second modal shape of the Nossa Senhora das Dores Church (Fig. 12b) involves modal displacements in $\mathrm{X}$ and $\mathrm{Y}$ directions, characterizing a torsion mode involving the lateral left wall and the interior arched wall, and the bell-tower with maximum displacements of 0.060 , in the arched wall, and 0.108 , in the top of the tower. The third modal shapes (Fig. 12c) involves modal displacements mainly observed in $\mathrm{X}$ direction, characterizing a transversal bending mode, in the arched wall, with modal dis-

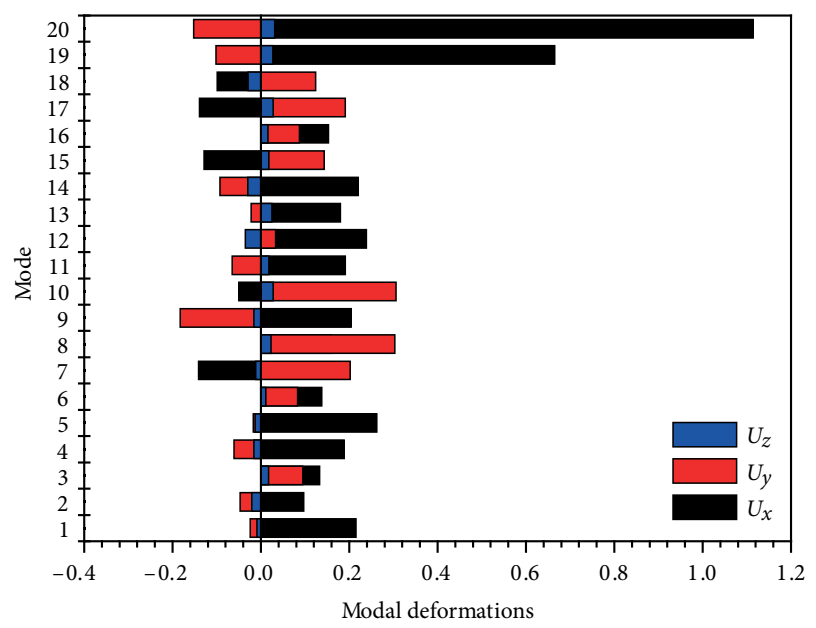

Fig. 12. Modal deformations of the first twenty modal shapes in the directions $X, Y$ and $Z$

placement of 0.133 , and the bell-tower, with 0.074 of modal deformation. These modal shapes also can be used for justify the accelerometers positioning adopted during ambient vibration testing.

Moreover the $6^{\text {th }}, 13^{\text {th }}$ and $18^{\text {th }}$ modal shapes requests several components of the church, characterizing global modes of the church, even with small periods. Analyzing the Figure 13 and Figure 14, it can be noted that the lateral left wall and the arched wall are the most requested elements and, consequently presents the most relevant modal displacements. The modal displacements in the latera left wall can be related with geometric properties, namely characterized as a slender element, and absence of clamping systems in the transversal direction of the church during the FEA formulation. In the arched wall, important values of modal displacements were expected, because the geometric of this type of structural elements presents more potential of deformation and torsion, as observed in (Bari, Orabona 2014).

In order to proceed with a static analysis of the Nossa Senhora das Dores Church, a numerical simulation considering the mechanical properties of the Table 4 and the dead load was carried out, the graphical results are shown by Figure 15, with linear elastic analysis. The results are presented in terms of Von-Mises stress (Fig. 15a) and normal stress in $\mathrm{Z}$ axes (Fig. 15b).

The Von-Mises stress can be used for identify potential zones under failure condition, as deeply discussed in (Brown, Miller 2006). Through the analysis of the Von-Mises stress distribution on the Nossa Senhora das Dores Church, it can be noted that the main stresses are located at the area surrounding the 
arched doors, especially in the doors of the first level of the main façade, and they occur for a maximum value of $0.58 \mathrm{MPa}$, representing 3.62 times than the tensile strength adopted in the model. This way, the static analysis noticed that the numerical model presents agreement with the church structural behavior, once that cracks founded and represented in the Figure 5 can be totally related with the tensions found by numerical analysis.

Positive values of normal stress can be mainly identified in the surrounding opened regions, as the arches in the doors and in the windows. In the main
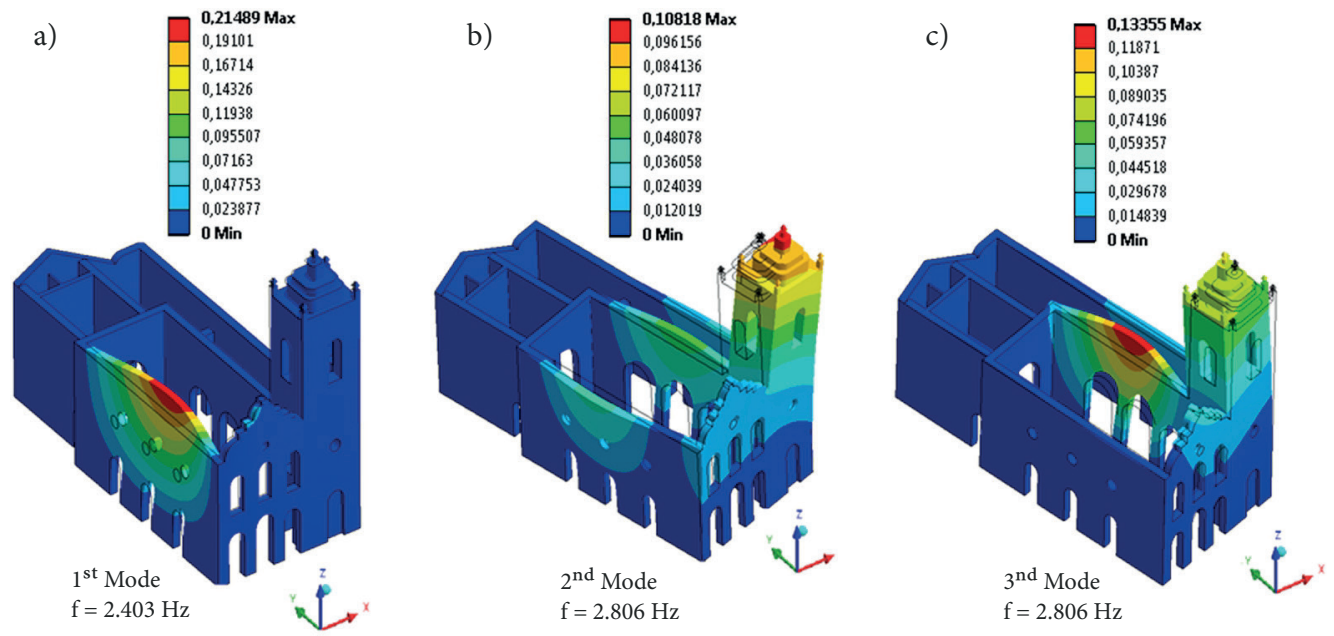

Fig. 13. First three modal shapes of the Nossa Senhora das Dores Church

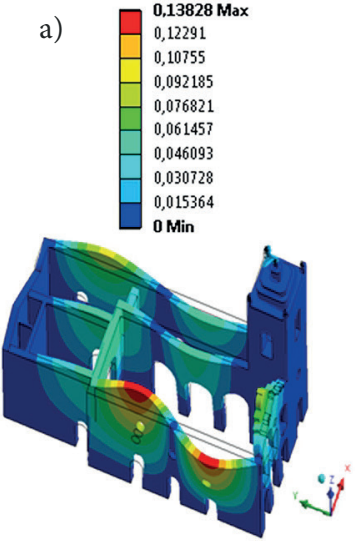

$6^{\text {st }}$ Mode $\mathrm{f}=4.925 \mathrm{~Hz}$
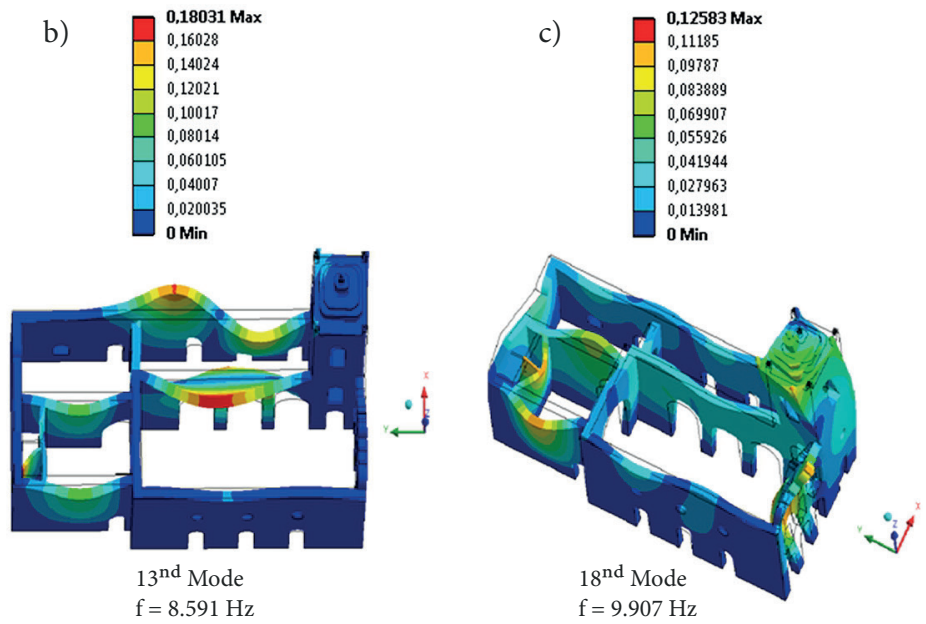

Fig. 14. 6th, 13th and 18th modal shapes of the Nossa Senhora das Dores Church
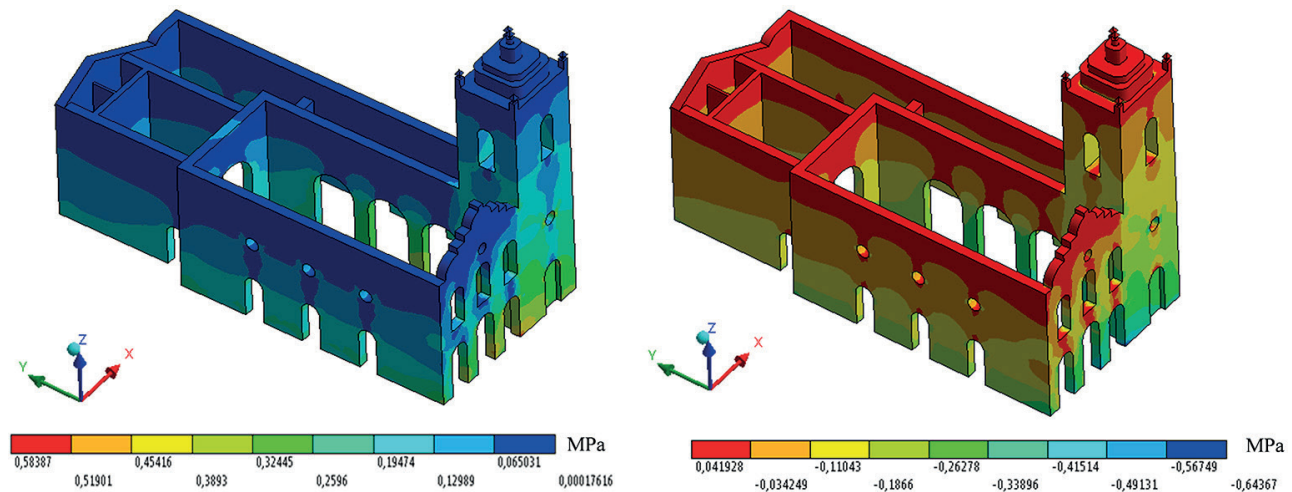

Fig. 15. Static analysis of the Nossa Senhora das Dores Church: Von-Mises stress (a) and normal stress in Z axes (b) 
façades, positive values of normal stress indicated the existence of tensions specially between the top of the arches of the doors and the bottom of the windows, while negative values of normal stress are related with compression. However, $0.643 \mathrm{MPa}$ was the maximum value of compressive stress in $\mathrm{Z}$, while the maximum value for tension stress was identified as $0.04 \mathrm{MPa}$. These values are inferior than load capacity of the clay brick masonries, here stated as 3.20 MPa (compressive strength) and 0.16 MPa (tensile strength).

\section{Conclusions}

In this work, the ambient vibration testing of the Nossa Senhora das Dores Church, an important heritage construction for Sobral community, was carried out as way of to collect information for updating a numerical model allowing it employment in furthers hypothetic scenarios, as well to assess the degradation of the church along the time.

The numeric and experimental dynamic investigation of the Nossa Senhora das Dores Church was performed with FEA and OMA, and the strategies employed during the ambient vibration characterization was described, analyzed and the results used in the definition of the final numerical model.

While FEA allowed the correct positioning of the accelerometers in the church, the OMA permitted the identification of the first five fundamental frequencies of the church, that are $2.391 \mathrm{~Hz}, 2.880 \mathrm{~Hz}, 3.125 \mathrm{~Hz}$, $3.466 \mathrm{~Hz}$ and $4.541 \mathrm{~Hz}$, and to characterize its respective modes. Based on the natural frequencies identify by OMA, the numerical model was updating and the first twenty modal shapes information were extracted, allowing to identify that modal displacements in $\mathrm{X}$ axes presents a most percentage of effective modal mass for modal shapes than in Y axes. Also, the graphical representation of the first three modal shapes were obtained, as well the modes with most elements requested, namely $6^{\text {th }}, 18^{\text {th }}$ and $20^{\text {th }}$ modes.

A linear static analysis was carried out and the $3 \mathrm{D}$ graphic representation of the Von-Mises stresses and normal stresses (in $\mathrm{Z}$ axes) distribution along the church were knew. These analyses allowed to identify the maximum values of stress in the church components, as well to state that under the scenarios considered in this paper, the church is safety. And comparison between the damages found on the church with the results of the FEA, allowed to state a relation between them.
Finally, the present work contributes for knowledge acquisition on the structural behavior of Brazilian heritage construction, through description of the strategies employed and even by the dynamic information collected. The information provided by this study can be useful for safety assessment of the heritage construction under dramatic scenarios, as seismic occurrences or structural degradation, as well its can be used for support of decisions on structural maintenance and risk reduction.

\section{Acknowledgements}

This work was financially supported by: Projects POCI-01-0145-FEDER-007457 - CONSTRUCT - Institute of R\&D in Structures and Construction and UID/ EEA/50008/2013. funded by FEDER funds through COMPETE2020 - Programa Operacional Competitividade e Internacionalização (POCI) - and by national funds through FCT.

The authors would like to acknowledge the Instituto do Patrimônio Histórico e Artístico Nacional (IPHAN) and Paroquia de Nossa Senhora da Conceição in Sobral for all support and useful informations for development of this work.

Esequiel Mesquita acknowledges CAPES through the fellowship number 10023/13-5. CAPES Foundation. Ministry of Education of Brazil. Francisco Brandão acknowledges the University State Vale do Acaraú. by research fellowship. and Paulo Antunes acknowledges FCT for the Postdoctoral fellowship SFRH/BPD/76735/2011.

\section{References}

ABNT. 1980. NBR 6120: Cargas para o cálculo de estruturas de edificações. Brazil.

Bari, P.; Orabona, V. E. 2014. Assessment of masonry arches and domes by simple models Fabrizio Palmisano 5(1).

Beskhyroun, S.; Wegner, L. D.; Sparling, B. F. 2012. New methodology for the application of vibration-based damage detection techniques, Structural Control and Health Monitoring 19(8): 632-649. https://doi.org/10.1002/stc.456

Boscato, G.; Dal Cin, A.; Ientile, S; Russo, S. 2016. Optimized procedures and strategies for the dynamic monitoring of historical structures, Journal of Civil Structural Health Monitoring 6(2): 265-289. https://doi.org/10.1007/s13349-016-0164-9

Branco, M. E. M. 2007. Reforço Sísmico de Edifícios de Alvenaria. Universidade Técnica de Lisboa.

Brincker, R.; Zhang, L.; Andersen, P. 2001. Modal identification of output-only systems using frequency domain decomposition, Smart Materials and Structures 10(3): 441. https://doi.org/10.1088/0964-1726/10/3/303 
Brown, M. W.; Miller, K. J. 2006. A theory for fatigue failure under multiaxial stress-strain conditions, ARCHIVE: Proceedings of the Institution of Mechanical Engineers 1847-1982 (vols 1-196), 187(1973): 745-755.

Brownjohn, J. M. W. 2003. Ambient vibration studies for system identification of tall buildings, Earthquake Engineering and Structural Dynamics 32(1): 71-95. https://doi.org/10.1002/eqe.215

CIB. 2010. Guide for the structural rehabilitation of heritage buildings. $1^{\text {st }}$ ed. Rotterdam: CIB.

dei Ministri, P. del C. 2011. Linee guida per la valutazione e la riduzione del rischio sismico del patrimonio culturale con riferimento alle Norme Tecniche per le Costruzioni di cui al decreto del Ministero delle Infrastrutture e dei trasporti del 14 gennaio 2008 (09/02/2011). Italy.

Delgado, J. 2013. Avaliação sísmica de um edifício crítico em alvenaria. Instituto Superior Técnico de Lisboa.

Gentile, C.; Saisi, A. 2007. Ambient vibration testing of historic masonry towers for structural identification and damage assessment, Construction and Building Materials 21(6): 13111321. https://doi.org/10.1016/j.conbuildmat.2006.01.007

Hans, S.; Boutin, C.; Ibraim, E.; Roussillon, P. 2005. In situ experiments and seismic analysis of existing buildings. Part I: Experimental investigations, Earthquake Engineering \& Structural Dynamics 34(12): 1513-1529. https://doi.org/10.1002/eqe.502

Ivanovic, S. S.; Trifunac, M. D.; Todorovska, M. I. 2000. Ambient vibration tests of structure - a review, ISET Journal of Earthquake Technology 37(4): 165-197.

Le, T.; Tamura, Y. 2009. Modal identification of ambient vibration structure using frequency domain decomposition and wavelet transform, in Proceedings of the $7^{\text {th }}$ Asia-Pacific Conference on Wind Engineering, 8-12 November 2009, Taipei, Taiwan.

Magalhães, F. 2010. Operational modal analysis for testing and monitoring of bridges and special structures, Doctor, 297.

Magalhães, F.; Cunha, A.; Caetano, E. 2012. Vibration based structural health monitoring of an arch bridge: From automated OMA to damage detection, Mechanical Systems and Signal Processing 28: 212-228. https://doi.org/10.1016/j.ymssp.2011.06.011

Martins, N.; Caetano, E.; Diord, S.; Magalhães, F.; Cunha, Á. 2014. Dynamic monitoring of a stadium suspension roof: wind and temperature influence on modal parameters and structural response, Engineering Structures 59: 80-94. https://doi.org/10.1016/j.engstruct.2013.10.021

Mesquita, E.; Antunes, P.; Coelho, F.; André, P.; Arêde, A.; Varum, H. 2016. Global overview on advances in structural health monitoring platforms, Journal of Civil Structural Health Monitoring 6(3): 461-475.

https://doi.org/10.1007/s13349-016-0184-5

Mesquita, E.; Arêde, A.; Silva, R.; Rocha, P.; Gomes, A.; Pinto, N.; Antunes, P.; Varum. H. 2017. Structural health monitoring of the retrofitting process, characterization and reliability analysis of a masonry heritage construction, Journal of Civil Structural Health Monitoring 7(3). https://doi.org/10.1007/s13349-017-0232-9

Ministero Delle Infrastrutture E Dei Trasporti. 2008. Norme Tecniche per le Costruzioni. Italy.

Neves, C. 2008. Análise Sísmica de um Edifício da Baixa Pombalina. Instituto Superior Técnico.

Ortega, J.; Vasconcelos, G.; Lourenço, P. B.; Rodrigues, H.; Varum, H. 2015. Seismic behaviour assessment of vernacular isolated buildings, in M. R. Correia, P. B. Lourenço, H. Varum (Eds.). Seismic retrofitting: learning from vernacular architecture. $1^{\text {st }}$ ed. London: Taylor \& Francis, 203-212.

Potenza, F.; Federici, F.; Lepidi, M.; Gattulli, V.; Graziosi, F.; Colarieti, A. 2015. Long-term structural monitoring of the damaged Basilica S. Maria di Collemaggio through a lowcost wireless sensor network, Journal of Civil Structural Health Monitoring 5(5): 655-676. https://doi.org/10.1007/s13349-015-0146-3

Rytter, A. 1993. Vibrational based inspection of civil engineering structures. University of Aalborg.

Spencer, B. F; Ruiz-Sandoval, M. E.; Kurata, N. 2004. Smart sensing technology: opportunities and challenges, Structural Control and Health Monitoring 11(4): 349-368. https://doi.org/10.1002/stc.48

STA Data. 20017. 3muri. Torino.

Ubertini, F.; Gentile, C.; Materazzi, A. L. 2013. Automated modal identification in operational conditions and its application to bridges, Engineering Structures 46(ii): 264-278. https://doi.org/10.1016/j.engstruct.2012.07.031

Yun, G. J.; Lee, S. G.; Carletta, J.; Nagayama, T. 2011. Decentralized damage identification using wavelet signal analysis embedded on wireless smart sensors, Engineering Structures 33(7): 2162-2172. https://doi.org/10.1016/j.engstruct.2011.03.007 
Esequiel MESQUITA was born in Iraucuba, Ceará, Brazil, on April 1989. In 2012 he received the bachelor degree in Civil Engineering by Universidade Estadual Vale do Acaraú and the PhD in Civil Engineering in 2017 from Faculty of Engineering of University of Porto, with doctoral fellowship from CAPES Foundation, Ministry of Education of Brazil. He has experience in materials characterization and durability of reinforced concrete structures, and he current research interests include structural health monitoring, optical sensors, structural risk assessment, structural safety maintenance, assessment, strengthening and repair of existing structures and built heritage conservation. Current he is the Head of Laboratory of Civil Engineering of Nuclei of Industrial Technology of Ceará State - NUTEC.

Francisco BRANDÃO was born in Mucambo, Ceará, Brazil, on July 1992. In 2012 he received the Technical License in Electrotechnology by Instituto Federal de Educação, Ciência e Tecnologia do Ceará (IFCE) and the bachelor degree in Civil Engineering in 2017 from Universidade Estadual Vale do Acaraú. During the academic year 2014/2015 he studied at Politecnico di Torino with undergraduate fellowship from CAPES Foundation, Ministry of Education of Brazil. He has experience in numerical modeling of masonry structures, seismic analysis of heritage constructions and dynamic identification of structures.

Aldecira DIOGENES received the bachelor degree in Civil Engineering by Universidade de Fortaleza in 2007, and the M.Sc. Degree in Civil Engineering in 2011 from Universidade Federal do Ceará. She is Assistant Professor at Universidade Estadual Vale do Acaráu, Brazil and PhD Student at Universidade Federal do Ceará. She has experience in materials characterization and structural analysis, and she current research interests include structural health monitoring, structural risk assessment, strengthening and repair of existing structures and built heritage conservation.

Paulo ANTUNES was born in Mealhada, Portugal, on May 1977. He received a Physics Engineering degree in 2005, the M.Sc. in Applied Physics in 2007 and the PhD in Physics Engineering in 2011 from the Universida de de Aveiro, Portugal. Currently he is working under a post-doctoral research fellowship from Fundacão para a Ciência e a Tecnologia in the Instituto de Telecomunicacões and in the Departamento de Física from the Universidade de Aveiro, Aveiro, Portugal. His current research interests include the study and simulation of fiber Bragg gratings, optical fiber sensors for static and dynamic measurements, data acquisition, and sensor net-works for structural monitoring.

Humberto VARUM was born in Salreu, Portugal, on October 1970. He is Full Professor in the Structures Division of the Civil Engineering Department at University of Porto, Portugal. He is engaged in large-scale experimental testing and nonlinear analytical modeling of structural systems. In his teaching, he has specialized in the seismic engineering, theory of structures, and conservation of structures. His current research interests include assessment, strengthening and repair of existing structures, structural testing and modeling, reliability of structures, earthquake engineering, and built heritage conservation. 